\title{
PENDETEKSI LEVEL FLUIDA MENGGUNAKAN METODE FLOAT MAGNETIC LEVEL GAUGE BERBASIS HUMAN MACHINE INTERFACE (HMI)
}

\author{
Miranty $^{1)}$, Fahrul $^{2)}$ dan Agus Salim Opu ${ }^{3)}$ \\ 1,2 Teknik Listrik dan Instalasi, Politeknik Industri Logam Morowali, \\ Jl. Trans Sulawesi Desa Labota Kec. Bahodopi Kab. Morowali \\ ${ }^{3}$ Teknik Kimia Mineral, Politeknik ATI Makassar \\ Jl. Sunu No.220 Kota Makassar \\ Email: ${ }^{1}$ miranty.antz407@gmail.com
}

\begin{abstract}
In this present technology era, human needs of the intelligent equipment systems that automatically do all task itself, are increased. For designing that equipment, a component that can calculate, remember, and also make a decision is required. Computer has that ability, but only using computer for this purpose is not efficient. So we use the computer with a microcontroller.

By using Float Magnetic Level gauge method in microcontroller, fluids level can be detector by a magnet system that can float as triggers of reed switch based on level change of fluids.

The result is level in percent unit and it is displayed on interface that named Human Machine Interface in real time. Measurement on fluid level sensor is when the sensor floating in minimum level, it will give $4 \mathrm{~mA}$ value as the signal output. And then when the sensor floating in maximum level, it will give 20mA value as the signal output. That value is the standard value for sensor signal output in industry. After converting the value of signal ouput current to voltage value, it found out that the level sencor has $98 \%$ accurancy.
\end{abstract}

Keyword: Measurement, Level, Fluids, Human Machine Interface, 4-20mA

\begin{abstract}
ABSTRAK
Pada era teknologi saat ini, kebutuhan manusia terhadap sistem peralatan cerdas yang dapat melakukan pekerjaan sendiri secara otomatis semakin meningkat. Oleh karena itu untuk merancang sistem peralatan tesebut, dibutuhkan sebuah sistem yang dapat menghitung, mengingat, dan mengambil keputusan. Komputer memiliki kemampuan tersebut, namun masih kurang efisien jika hanya menggunakan computer untuk keperluan tersebut. Oleh karena itu computer dapat dikombinasikan dengan mikrokontroler.

Menggunakan metode Float Magnetic Level Gauge pada mikrokontroler, ketinggian fluida dapat dideteksi dengan sistem magnet yang dapat mengapung sebagai pengaktif saklar reed switch berdasarkan perubahan level permukaan fluida.

Hasil pengukuran berupa level dalam satuan persen ditampilkan dalam sebuah sistem interface dengan tampilan animasi yang disebut Human Machine Interface (HMI) secara realtime. Hasil pengukuran driver sensor level saat kondisi fluida pada kondisi minimum adalah $4 \mathrm{~mA}$, dan pada kondisi fluida berada pada kondisi level maksimum adalah $20 \mathrm{~mA}$. Nilai tersebut sesuai dengan standar sinyal output sensor yang digunakan pada sistem instrumentasi industri. Setelah melakukan konversi hasil pengukuran arus menjadi tegangan, diperoleh tingkat ketelitian sensor sebesar $98 \%$. Kata kunci: Pengukuran, Level, Fluida, Human Machine Interface, 4-20mA
\end{abstract}

\section{PENDAHULUAN}

Kaveh \& Norouzi (2017). Kemajuan pesat dalam teknologi telah sampai pada berbagai variasi peralatan dengan kemampuan penginderaan level, pemantauan serta kemampuan mengontrol. Realisasi dari sensor level cairan telah menjadi layak melalui pengadopsian dari berbagai prinsip fisik.
Parameter yang membentuk pilihan alami untuk aplikasi spesifik oleh sensor level adalah sebagai berikut: (a) range pengukuran (b) resolusi (c) akurasi (d) karakteristik dari cairan dan (e) lingkungan. Fokus utamanya adalah tiga parameter awal, terutama dalam hal pengembangan sensor yang handal dan aman untuk cairan yang mudah terbakar yang berbahaya dan eksplosif. Penelitian 
tersebut berfokus pada proses yang berkaitan dengan pengembangan dari sistem otomasi pompa bahan bakar fosil untuk mengisi sebuah tangki penampungan. Metode yang ditawarkan adalah menggunakan sensor high-end level drop recognition yang bekerja berdasarkan prinsip kerja float magnetic level gauge dengan menggunakan LED sebagai indikator level.

Kalidoss, Praniha, Raveena, \& Revathy (2017) Mengukur level ketinggian dari cairan yang tersimpan merupakan tugas penting di berbagai industri kimia maupun pro-kimia dan juga industri kilang minyak. Berbagai metode ditawarkan untuk mengukur level cairan di dalam tangki penyimpanan. Pengukuran level berbasis gelombang elektromagnetik (contohnya: radar) merupakan sebuah metode bebas-kontak dan tidak rentan terhadap berbagai macam gangguan. Akan tetapi, sinyal radar dari wide-band maupun ultra-wide seharusnya ditransmisikan untuk mencapai akurasi yang dbutuhkan. Penelitian ini membandingkan dua metode pengukuran level yang mengunakan radar dan gelombang elektromagnetik sebagai sensor.

Syahreza dan Irhamni (2009). Penelitian dilakukan dengan melakukan pembuatan sistem monitoring ketinggian cairan (air) dengan menggunakan sensor ultrasonik sebagai sensor pendeteksi ketinggiannya, dan LCD sebagai display output yang menampilkan hasil pengolahan data mikrokontroler dari sensor ultrasonik. Hasil yang didapatkan dari pembuatan sistem monitoring tersebut adalah ketinggian air yang terdeteksi terbagi atas 3 level.

Samian dan Supardi (2011) pendeteksi ketinggian air dengan menggunakan multimode fiber coupler sebagai sensor. Sensor ini bekerja dengan memperhatikan perubahan pressure hidrostatis akibat perubahan ketinggian air di dalam tangki. Pressure hidrostatis ini akan menggeser membran yang telah diberi bahan reflector. Dan hasil dari eksperimen penelitian ini menunjukkan bahwa dynamic range ketinggian air yang dapat dimonitor oleh sensor adalah dari 45 - $320 \mathrm{~mm}$.

Berdasarkan latar belakang yang telah dipaparkan di atas, maka penulis bermaksud dan ingin merancang sekaligus membuat suatu alat dan sistem yang dapat diaplikasikan di industri. Dengan Menggunakan metode Float Magnetic Level Gauge pada mikrokontroler, ketinggian fluida dapat dideteksi dengan sistem magnet yang dapat mengapung sebagai pengaktif saklar reed switch berdasarkan perubahan level permukaan fluida. Fluida yang digunakan sebagai sampel adalah air dan oli bekas yang mana mempunyai massa jenis yang berbeda. Hasil pengukuran berupa level dalam satuan persen (\%) ditampilkan dalam sebuah sistem interface dengan tampilan animasi yang disebut Human Machine Interface (HMI) secara realtime.

\section{METODE PENELITIAN}

Dalam melakukan proses penelitian, diperlukan adanya tahapan-tahapan agar penelitian tersebut dapat berjalan sesuai dengan yang telah direncanakan. Oleh karena itu, pada penelitian ini mempunyai tahapan-tahapan alur penelitian seperti ditampilkan pada gambar flowchart yang ditunjukkan oleh Gambar 1. 

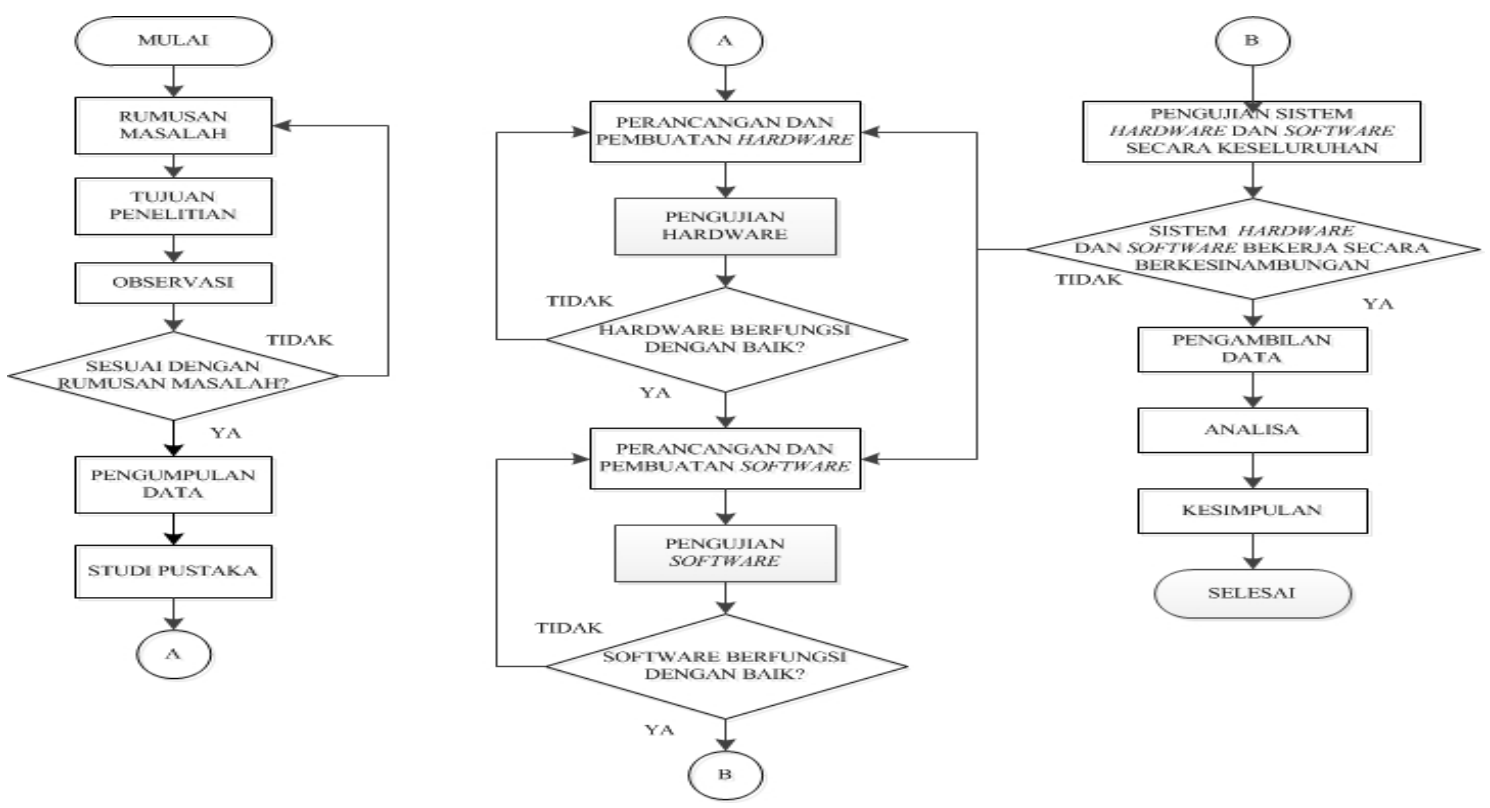

Gambar 1. Flowchart Penelitian

Perancangan dan pembuatan hardware mencakup semua hardware yang akan digunakan pada penelitian ini, seperti perancangan dan pembuatan tangki tempat fluida, float magnetic level gauge, current to voltage converter, Analog to Digital Converter Modul $(A D C)$, modul mikrokontroler, modul transmitter/receiver data, motor driver, catu daya regulator. Pengujian meliputi fungsi, dan karakteristik masing-masing hardware tersebut. Apabila semua hardware telah layak sesuai dengan fungsi dan karakteristiknya masingmasing, maka hardware tersebut siap untuk dikombinasikan dengan software. Perancangan dan pembuatan software ini meliputi software mikroPascal yang digunakan pada modul mikrokontroler, delphi digunakan pada komputer yang berfungsi sebagai software penghubung antara mikroPascal dengan flash. Sedangkan software flash sendiri berfungsi untuk menampilkan animasi dilayar monitor. Proses ini harus dilakukan dengan mengkombinasikan antara hardware dan software, sehingga dapat terlihat dengan jelas hasil dari software tersebut agar sesuai dengan fungsinya masing-masing.

Gambar 2 merupakan diagram blok dari sistem yang dirancang, yaitu mikrokontroler mengambil peran penting sebagai pusat kontrol sistem. Fluida dialirkan oleh motor pump 1 dan 2 ke dalam tangki untuk di ukur. Pengukuran level ketinggian fluida diukur menggunakan satu float magnetic level gauge pada masing-masing tangki. Kedua float magnetic level gauge tersebut menghasilkan output berupa arus 4-20 mA, kemudian dikonversi menjadi tegangan dengan menggunakan current to voltage converter dengan range 1-5 Volt. Pada ADC modul, tegangan analog di konversi menjadi bitbit digital dan diteruskan ke mikrokontroler.

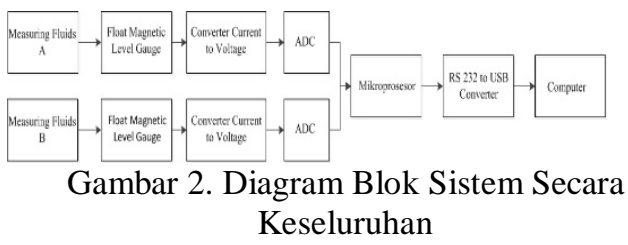

Mikrokontroler menerima dan mengirim perintah berupa input maupun output pada driver untuk mengontrol peralatan seperti sensor, solenoid valve, bahkan motor pump agar dapat beroperasi sesuai perintah yang diinginkan. Motor pump diberi perintah oleh user melalui computer ke mikrokontroler, untuk mengalirkan fluida dari tempat penampungan ke tangki fluida. 
Sedangkan solenoid valve berfungsi untuk menguras fluida dari dalam tangki. Pengontrolan tersebut dapat dilakukan user hanya dengan meng-klik tombol yang tampil di layar komputer. Dari keseluruhan sistem berupa diagram blok dan penjelasan mengenai sistem tersebut, maka sistem tersebut dapat dikatakan sebagai sistem yang berbasis Human Machine Interface (HMI) secara real time.

\section{HASIL DAN PEMBAHASAN}

Setelah melakukan perancangan serta melakukan pengujian sistem secara keseluruhan, maka didapatkan hasil sistem berupa fisik hardware, tampilan HMI dan data dari hasil pengujian berupa level fluida baik dalam bentuk nilai arus 4-20 mA maupun dalam nilai persentase $0-100 \%$. Oleh karena itu, untuk lebih jelasnya seperti yang ditampilkan oleh beberapa gambar dan tabel berikut.

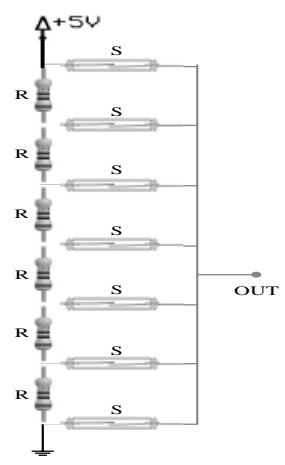

Gambar 3. Skema Rangkaian Sensor Float

Magnetic Level Gauge

Sumber: Miranty (2017)

Sensor magnetic level gauge terdiri dari resistor yang dihubung seri, dan reed switch yang terpasang diantara tiap resistor. Reed switch tersebut akan menutup (close), apabila terinduksi oleh medan magnet. Setiap reed switch menghasilkan nilai tegangan output yang berbeda-beda, berdasarkan pergerakan posisi magnet. Nilai tegangan tersebut, merepresentasikan posisi magnet yang merupakan posisi jarak perubahan suatu objek yang diukur.
Hasil analisis perbandingan perhitungan terhadap percobaan pada dua jenis sampel, yaitu air dan oli bekas terlampir dalam bentuk tabel berikut:

Tabel 1. Perbandingan Hasil Perhitungan Terhadap Percobaan untuk Sampel Air

\begin{tabular}{|c|c|c|c|}
\hline No. & $\begin{array}{c}\text { Arus (mA) } \\
\text { Perhitunga } \\
n\end{array}$ & $\begin{array}{l}\text { Arus (mA) } \\
\text { Percobaan }\end{array}$ & $\begin{array}{c}\text { Level } \\
(\%)\end{array}$ \\
\hline 1 & 4 & 4 & 0 \\
\hline 2 & 4,08 & 4,08 & 0,5 \\
\hline 3 & 4,8 & 4,8 & 5 \\
\hline 4 & 5,6 & 5,56 & 10 \\
\hline 5 & 6,4 & 6,24 & 15 \\
\hline 6 & 7,2 & 7,04 & 20 \\
\hline 7 & 8 & 8,16 & 25 \\
\hline 8 & 8,8 & 8,68 & 30 \\
\hline 9 & 9,6 & 9,6 & 35 \\
\hline 10 & 10,4 & 10,4 & 40 \\
\hline 11 & 11,2 & 11,2 & 45 \\
\hline 12 & 12 & 11,84 & 50 \\
\hline 13 & 12,8 & 13,08 & 55 \\
\hline 14 & 13,6 & 13,4 & 60 \\
\hline 15 & 14,4 & 14,44 & 65 \\
\hline 16 & 15,2 & 15 & 70 \\
\hline 17 & 16 & 15,72 & 75 \\
\hline 18 & 16,8 & 16,64 & 80 \\
\hline 19 & 17,6 & 17,52 & 85 \\
\hline 20 & 18,4 & 18,52 & 90 \\
\hline 21 & 19,2 & 19,24 & 95 \\
\hline 22 & 20 & 19,72 & 100 \\
\hline
\end{tabular}

Tabel 2. Perbandingan Hasil Perhitungan Terhadap Percobaan untuk Sampel Oli Bekas

\begin{tabular}{cccc}
\hline No. & $\begin{array}{c}\text { Arus (mA) } \\
\text { Perhitungan }\end{array}$ & $\begin{array}{c}\text { Arus (mA) } \\
\text { Percobaan }\end{array}$ & $\begin{array}{c}\text { Level } \\
\mathbf{( \% )}\end{array}$ \\
\hline 1 & 4 & 4 & 0 \\
\hline 2 & 4,16 & 4,16 & 1 \\
\hline 3 & 4,8 & 4,84 & 5 \\
\hline 4 & 5,6 & 5,6 & 10 \\
\hline 5 & 6,4 & 6,36 & 15 \\
\hline 6 & 7,2 & 7,08 & 20 \\
\hline 7 & 8 & 7,84 & 25 \\
\hline 8 & 8,8 & 8,72 & 30 \\
\hline 9 & 9,6 & 9,6 & 35 \\
\hline 10 & 10,4 & 10,4 & 40 \\
\hline 11 & 11,2 & 11,04 & 45 \\
\hline 12 & 12 & 11,96 & 50 \\
\hline 13 & 12,8 & 12,76 & 55 \\
\hline 14 & 13,6 & 13,6 & 60 \\
\hline 15 & 14,4 & 14,2 & 65 \\
\hline 16 & 15,2 & 15 & 70 \\
\hline 17 & 16 & 15,8 & 75 \\
\hline 18 & 16,8 & 16,8 & 80 \\
\hline 19 & 17,6 & 17,4 & 85 \\
\hline 20 & 18,4 & 18,08 & 90 \\
\hline 21 & 19,2 & 19 & 95 \\
\hline 22 & 20 & 19,68 & 100 \\
\hline
\end{tabular}

Setelah didapatkan perbandingan antara hasil perhitungan dengan percobaan, maka dapat dibuat tampilan grafik sebagaimana yang ditunjukkan Gambar 4 dan Gambar 5. 
PERBANDINGAN HASIL PERHITUNGAN DAN PERCOBAAN DENGAN SAMPEL AIR

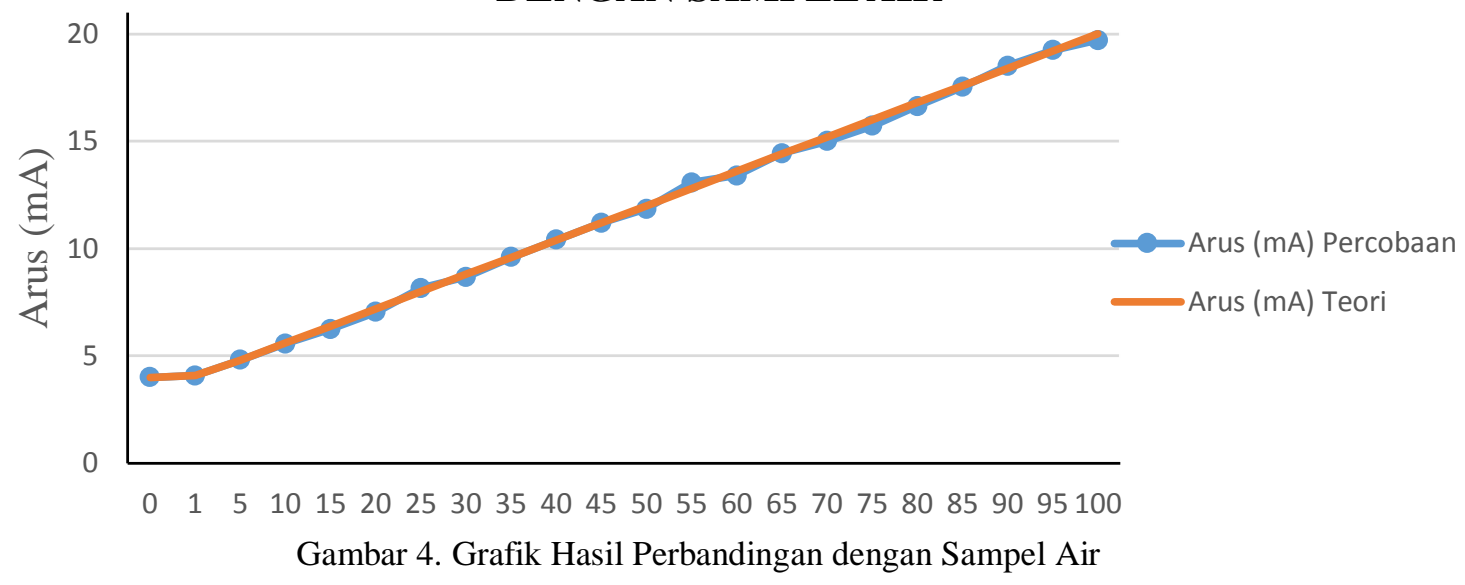

PERBANDINGAN HASIL PERHITUNGAN DAN PERCOBAAN DENGAN SAMPEL OLI BEKAS

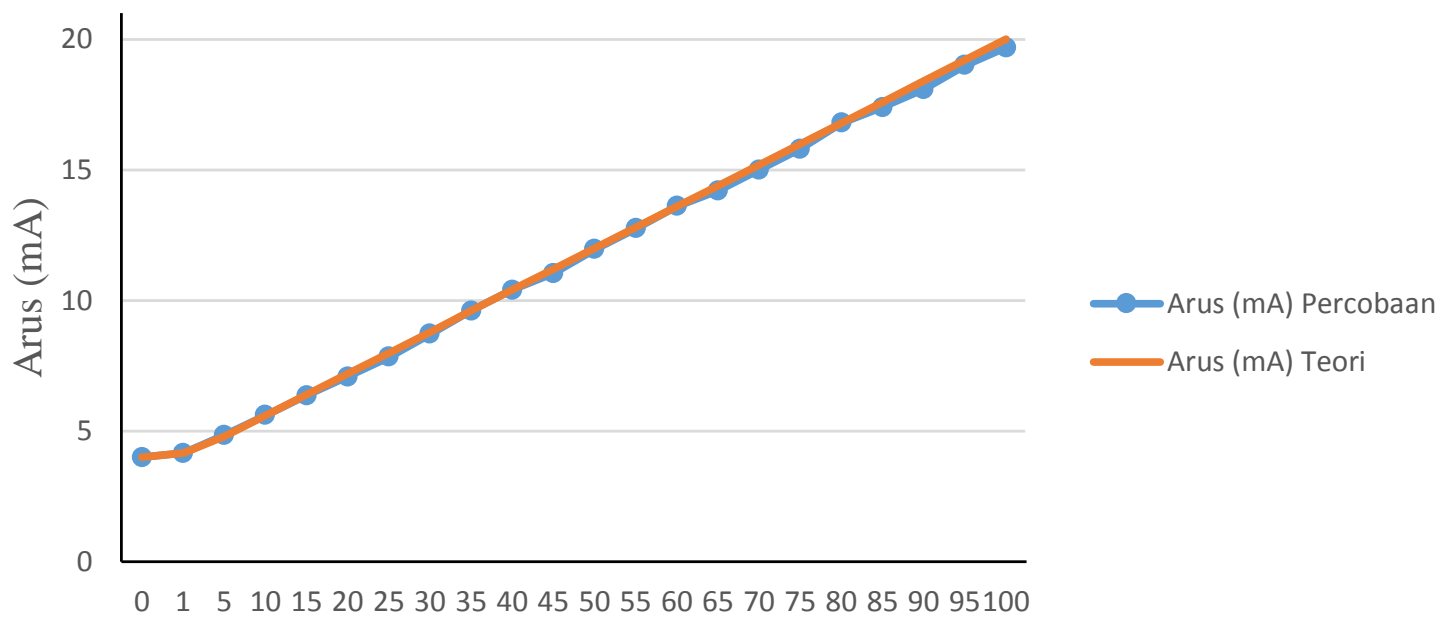

Gambar 5. Grafik Hasil Perbandingan dengan Sampel Oli Bekas

Perhitungan menentukan keakuratan sensor level bertujuan untuk menentukan ketelitian sensor yang telah dirancang. Dari hasil perhitungan tersebut, dapat disimpulkan apakah sensor tersebut layak atau tidak untuk digunakan.

Diketahui, batas maksimum ketinggian pengukuran sensor level ini adalah 90 cm. Sehingga ketinggian maksimum 90 $\mathrm{cm}$ adalah kondisi ketinggian maksimum $100 \%$. Penentuan kondisi 1\% didapat dengan perhitungan $\frac{90 \mathrm{~cm}}{100 \%}=0.9 \mathrm{~cm} /$ $1 \%$. Sampel yang diambil secara acak sebanyak 8 kali dengan ketentuan range
$5 \%$ atau $4.5 \mathrm{~cm}$. Perhitungan ini menggunakan rumus berikut:

$\bar{x}=\frac{\sum x_{n}}{s}$

Dimana:

$\bar{x}=$ nilai rata-rata secara keseluruhan $\sum x_{n}=$ jumlah (total) keseluruhan nilai xn yang di dapat dari hasil perhitungan (nilai maksimum nilai minimum) sampel.

$\mathrm{s} \quad=$ jumlah sampel

Setelah mendapatkan nilai $\bar{x}$, penentuan keakuratan sensor sudah dapat dilakukan. penentuan keakuratan tersebut menggunakan rumus berikut: 
keakuratan sensor $=\frac{\bar{x}}{\text { range }} \times 100 \%$

Dimana:

$\bar{x}=$ nilai rata-rata secara keseluruhan Range $=$ nilai range pengukuran

Sampel data digunakan untuk menentukan tingkat keakuratan dari sensor level yang telah dirancang. Hasil dari perhitungan dari sampel data dapat memberikan keterangan nilai tingkat keakuratan sensor level yang dirancang serta berapa nilai errornya sehingga dapat disimpulkan layak atau tidaknya sensor level tersebut digunakan. Tabel sampel data untuk sensor level air terlampir pada Tabel 3 di bawah ini:

Tabel 3. Hasil Pengukuran Level Untuk Penentuan Tingkat Keakuratan Sensor Level

\begin{tabular}{|c|c|c|c|c|c|c|}
\hline \multirow[t]{2}{*}{ No. } & \multicolumn{2}{|c|}{ Titik Awal } & \multicolumn{2}{|c|}{ Titik Akhir } & \multicolumn{2}{|c|}{$\begin{array}{c}\mathrm{X}_{\mathrm{n}}=(\text { Titik } \\
\text { Akhir - Titik } \\
\text { Awal) }\end{array}$} \\
\hline & $(\mathrm{cm})$ & (\%) & $(\mathrm{cm})$ & (\%) & $(\mathrm{cm})$ & (\%) \\
\hline 1. & 8.37 & 9.31 & 12.78 & 14.21 & 4.41 & 4.90 \\
\hline 2. & 12.78 & 14.21 & 17.21 & 19.13 & 4.43 & 4.92 \\
\hline 3. & 17.21 & 19.13 & 21.62 & 24.03 & 4.41 & 4.90 \\
\hline 4. & 21.62 & 24.03 & 26.04 & 28.94 & 4.42 & 4.91 \\
\hline 5. & 26.04 & 28.94 & 30.45 & 33.84 & 4.41 & 4.90 \\
\hline 6. & 30.45 & 33.84 & 34.42 & 38.25 & 3.97 & 4.41 \\
\hline 7. & 34.42 & 38.25 & 39.27 & 43.64 & 4.85 & 5.39 \\
\hline 8. & 39.27 & 43.64 & 43.68 & 48.54 & 4.41 & 4.9 \\
\hline
\end{tabular}

Berikut perhitungan untuk menentukan keakuratan sensor level dengan menggunakan sampel data pada Tabel 3. Perhitungan untuk Tangki 1

Diketahui :

$\begin{array}{ccc}\mathrm{x}_{1} & = & 4.93 \% \\ \mathrm{x}_{2} & = & 4.92 \% \\ \mathrm{X}_{3} & = & 4.9 \% \\ \mathrm{x}_{4} & = & 4.91 \% \\ \mathrm{X}_{5} & = & 4.9 \% \\ \mathrm{X}_{6} & = & 4.41 \% \\ \mathrm{X}_{7} & = & 5.39 \% \\ \mathrm{X}_{8} & = & 4.9 \\ \mathrm{~S} & = & 8 \\ \text { Range } & = & 5 \%\end{array}$

Ditanyakan : Keakuratan Sensor $=\ldots$ ?

Penyelesaian:

$$
\begin{aligned}
\sum x_{n}= & x_{1}+x_{2}+x_{3}+x_{4}+x_{5}+x_{6}+x_{7}+x_{8} \\
= & 4.93 \%+4.92 \%+4.9 \%+4.91 \% \\
& +4.9 \%+4.41 \%+5.39 \%+4.9 \% \\
= & 39.26 \%
\end{aligned}
$$

$$
\begin{aligned}
\bar{x} & =\frac{\sum x_{n}}{s} \\
& =\frac{39.26}{8}=4.90 \%
\end{aligned}
$$

Keakuratan Sensor

$$
\begin{gathered}
=\frac{\bar{x}}{\text { range }} \times 100 \% \\
=\frac{4.90 \%}{5 \%} \times 100 \%
\end{gathered}
$$

$=98 \%$ dengan nilai error sebesar $2 \%$

Dari hasil analisa untuk menentukan tingkat keakuratan pendeteksi level yang telah selesai dirancang, didapatkan hasil tingkat kekuratan sebesar 98\% dengan error 2\%. Terjadinya error 2\%, disebabkan karena toleransi dari komponen resistor yang digunakan adalah sebesar $5 \%$.

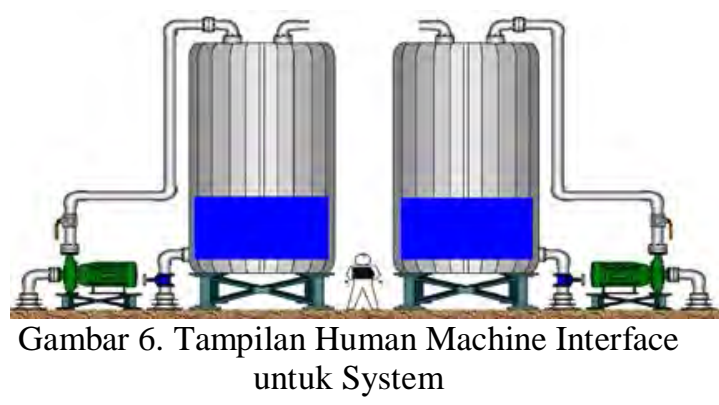

Bentuk fisik dari tampilan Human Machine Interface ditampilkan pada Gambar 6 di atas. Display Human Machine Interface ini dibuat dengan menggunakan dua macam software, yaitu Borland Delphi7 dan Adobe Flash Player. HMI ini, bekerja secara realtime, artinya setiap perubahan yang terjadi di lapangan akan ditampilkan pada display HMI ini.

\section{KESIMPULAN}

1. Sistem akuisisi data secara real time adalah suatu sistem yang sangat efisien dan handal digunakan pada Human Machine Interface, karena user dapat memonitor sekaligus mengontrol suatu sistem yang kompleks hanya dengan mengontrol melalui komputer, tanpa harus turun langsung ke lapangan untuk 
memonitor dan mengontrol sistem tersebut.

2. Tingkat keakuratan pendeteksi level yang dirancang mencapai 98\% dengan error $2 \%$. Terjadinya error 2\%, disebabkan karena Terjadinya error $2 \%$, disebabkan karena toleransi dari komponen resistor yang digunakan adalah sebesar $5 \%$..

3. Metode float magnetic level gauge adalah salah satu metode yang dapat diterapkan untuk semua jenis pengukuran ketinggian level fluida.

4. Level transmitter yang dirancang telah mampu menghasilkan nilai output analog berupa arus 4-20 mA, yang mana nilai output tersebut merupakan nilai output sensor yang sesuai dengan standar industri.

\section{DAFTAR PUSTAKA}

[1] Kalidoss, R., Praniha, R., Raveena, P., \& Revathy, C. (2017). Petrol Level Indicator with Automated Audio Alert System. 2017 International Conference on Wireless Communications, Signal Processing and Networking (WiSPNET) (pp. 537-539). Chennai, India: IEEE.

[2] Kaveh, S., \& Norouzi, Y. (2017). Non-uniform Sampling and SuperResolution Method to Increase The Accuracy of Tank Gauging Radar. IET Radar, Sonar \& Navigation, 788-796.

[3] Miranty, Affandi, A., \& Endroyono. (2017). Sistem Komunikasi Data Pada Band Ultra High Frequency (UHF) Menggunakan Protokol AX25 Untuk Tsunami Early Warning System. Surabaya: Institut Teknologi Sepuluh Nopember.

[4] Samian, \& Supardi. (2011). Sensor Ketinggian Air menggunakan Multimode Fiber Coupler. Jurnal Fisika FMIPA ITS.
[5] Syahreza, S., \& Irhamni. (2009). Rancang Bangun Sensor Ketinggian Air (Water Level) Menggunakan Transduser Ultrasonik Berbasis Mikrokontroler MCS51. Jurnal Rekayasa Elektrika.

[6] Wicaksono, H. (2009). Software dengan Wonderware InTouch: Dasar-Dasar Pemrograman. Yogyakarta: Graha Ilmu. 
Miranty, Fahrul dan Salim Opu. Pendeteksi Level Fluida... 